\title{
Research on Implementation Effect Evaluation and Improvement Strategies of "New Rural Cooperative Medical System" in Jilin Province
}

\author{
Lei li \\ Jilin agricultural university, college of humanities, Changchun130118, China \\ lilei@jlau.edu.cn
}

\begin{abstract}
New rural cooperative medical system (NCMS) is a rural cooperative medical system that is organized and guided by government, farmers voluntarily participate in, individual, collective and government party's finance, which takes the serious illness of farmers as the core, and it is one of the essential national health policy in our country. More than 10 years' practice has proved that the new rural cooperative medical system is suitable for China's national conditions. The implementation of the new rural cooperative medical system makes the problem that it is difficult and expensive for farmers to see a doctor alleviated to a certain degree. Even though great achievements have been made in the new rural cooperative medical system, it still has a big gap from the expectations of the farmers. Therefore, this paper evaluates on the new rural cooperative medical system effect in Jilin Province, understands the farmers' demand on the new rural cooperative medical system improvement, and improves the policy formulation of new rural cooperative medical system in the future.
\end{abstract}

Keywords: New rural cooperative medical system; Effect evaluation; Improvement; Policy formulation.

\section{Introduction}

China is a developing agricultural country, "three rural issues" is an essential issue that is always related to national development and stability. Establishing and improving the rural medical security system is the basic work of rural development, and it is also an inevitable requirement for the comprehensive construction of well-off society. In 2012, in the Party's eighteenth major reports, the requirement was clearly put forward of completing national health insurance system and establishing major disease protection and relief mechanisms. Whether the system can change the peasants' personal expense burden so as to effectively improve the benefit from the level of participation of farmers is always the key to deepen the reform of the medical and health care system [1,2]. As long as it is to ensure that the overall level of research can better promote the construction of the foundation, we need to show the rationality of the system design itself in accordance with the requirements of the objective. It doesn't just mean the increasing utilization rate for people in the future, more highlight how people better use this to carry out the medical security and the implementation results in the process of current construction and change [3]. In consequence, this paper evaluates on the effect of new rural cooperative medical system in Jilin Province, understands the farmers' demand on the new rural cooperative medical system improvement, and enhances the policy establishment of new rural cooperative medical system in the future.

\section{Implementation Effect Evaluation on the New Rural Cooperative Medical System in Jilin Province}

\subsection{Average Financing Situation of New Rural Cooperative Medical System in Jilin Province}

For per capita payment amount, from 2003 to 2015, per capita payment of farmers participated in Rural Cooperative in Jilin Province is increased from 10 Yuan to 90 Yuan. With the increase of annual per capita net income of farmers' year by year, the proportion of individual contributions accounted for annual net income of average per capita is also in moderate growth, increasing from $0.3 \%$ in 2003 to $0.8 \%$ in 2015 . It is specifically shown in table 1 [4]. 
Table 1 Comparison of individual payment and per capita annual income of new rural cooperative medical system in Jilin Province from 2003 to 2015

\begin{tabular}{|c|c|c|c|}
\hline Year & $\begin{array}{l}\text { Farmers' annual net income of } \\
\text { average per capita (Yuan) }\end{array}$ & $\begin{array}{l}\text { Per capita } \\
\text { (Yuan) }\end{array}$ & $\begin{array}{l}\text { Proportion of individual contributions accounted } \\
\text { for annual net income of average per capita }(\%)\end{array}$ \\
\hline 2003-2004 & 3223 & 10 & 0.3 \\
\hline 2005 & 3128 & 10 & 0.3 \\
\hline 2006 & 3352 & 10 & 0.3 \\
\hline 2007 & 4026 & 10 & 0.2 \\
\hline 2008 & 4430 & 10 & 0.2 \\
\hline 2009 & 5023 & 20 & 0.4 \\
\hline 2010 & 6082 & 30 & 0.5 \\
\hline 2011 & 6304 & 30 & 0.5 \\
\hline 2012 & 7236 & 50 & 0.7 \\
\hline 2013 & 9621 & 50 & 0.5 \\
\hline 2014 & 10780 & 60 & 0.6 \\
\hline 2015 & 11326 & 90 & 0.8 \\
\hline
\end{tabular}

\subsection{Coverage Situation of New Rural Cooperative Medical System in Jilin Province}

For the coverage situation of the new rural cooperative medical system, the new rural cooperative medical system pilot county (city) in Jilin Province is expanded from 6 in 2003 - 2004 to 9 in 2005, and 24 in 2006. It takes the lead in realizing the full coverage of the new rural cooperative medical system in 2007, namely the 67 Counties (City, District, and Development Zone) comprehensively launched the new rural cooperative medical system. It is shown in table 2 [3].

Table 2 Coverage of the new rural cooperative medical system in Jilin Province from 2003 to 2015

\begin{tabular}{|c|c|c|c|}
\hline Year & $\begin{array}{c}\text { Total number of County (City, } \\
\text { District, and Development Zone) }\end{array}$ & $\begin{array}{c}\text { Number of County (City, District, and } \\
\text { Development Zone) that has launched the } \\
\text { system }\end{array}$ & $\begin{array}{c}\text { Coverage } \\
\text { rate (\%) }\end{array}$ \\
\hline $2003-2004$ & 66 & 6 & 10.0 \\
\hline 2005 & 66 & 9 & 13.6 \\
\hline 2006 & 66 & 24 & 36.4 \\
\hline 2007 & 66 & 66 & 100 \\
\hline 2008 & 66 & 66 & 100 \\
\hline 2009 & 66 & 66 & 100 \\
\hline 2010 & 66 & 66 & 100 \\
\hline 2011 & 67 & 67 & 100 \\
\hline 2012 & 67 & 67 & 100 \\
\hline 2013 & 67 & 67 & 100 \\
\hline 2014 & 67 & 67 & 100 \\
\hline 2015 & 67 & 67 & 100 \\
\hline
\end{tabular}




\subsection{Utilization of New Rural Cooperative Medical Service in Jilin Province}

For hospitalization, from 2003 to 2015, the number of hospitalization of new rural cooperative medical in Jilin province is increased from 39266 to 1808233 , and the rate is increased from $2.1 \%$ to $12.9 \%$, which has the trend of increasing year by year trend. It is seen in table 3 and figure 1 [5].

Table 3 Hospitalization of farmers participated in rural cooperative medical in Jilin Province from 2003 to 2015

\begin{tabular}{|c|c|c|c|}
\hline Year & The number of farmers in rural cooperative medical & Times of hospitalization & $\begin{array}{c}\text { Hospitalization rate } \\
(\%)\end{array}$ \\
\hline $2003-2004$ & 1904055 & 39266 & 2.1 \\
\hline 2005 & 2026286 & 98772 & 4.9 \\
\hline 2006 & 6244150 & 241328 & 3.9 \\
\hline 2007 & 11624559 & 477236 & 4.1 \\
\hline 2008 & 12166049 & 639827 & 5.3 \\
\hline 2009 & 12514991 & 742903 & 5.9 \\
\hline 2010 & 12525405 & 887838 & 7.1 \\
\hline 2011 & 13020533 & 1054371 & 8.1 \\
\hline 2012 & 13281721 & 1217047 & 10.4 \\
\hline 2013 & 13583253 & 1412353 & 11.6 \\
\hline 2014 & 13687342 & 1587324 & 12.9 \\
\hline 2015 & 13943223 & 1808233 & \\
\hline
\end{tabular}

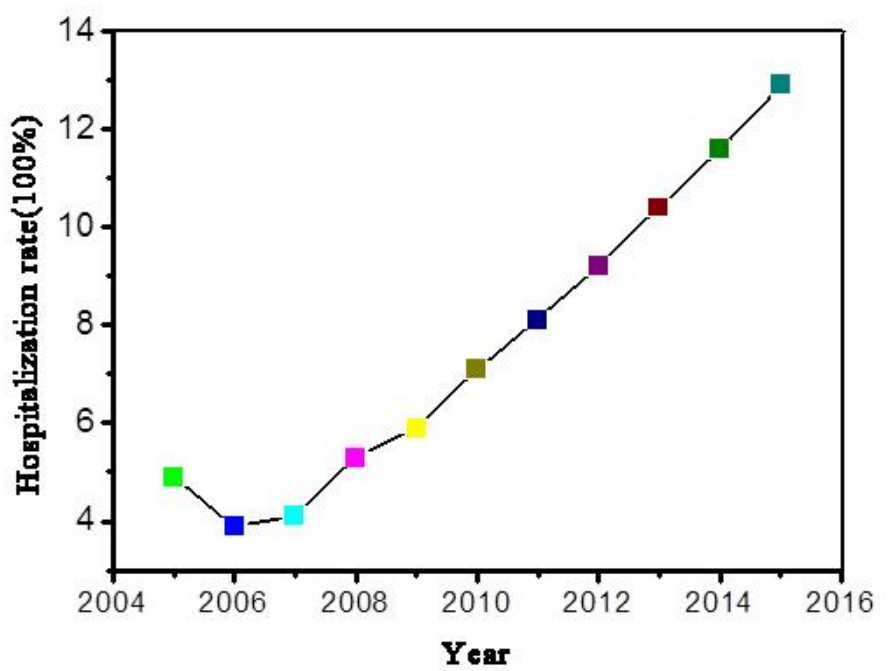

Figure 1 Hospitalization rate change trend of farmers participated in rural cooperative medical in Jilin Province from 2003 to 2015

Hospitalization of farmers participated in rural cooperative medical in different areas in Jilin Province in 2015: hospitalization rate in the western region is the highest (14.9\%), followed by the eastern region $(14.3 \%)$, and the least is the central region $(11.7 \%)$. The hospitalization rate in eastern and western regions is higher than that in the whole province (12.9\%), as shown in table 4. 
Table 4 Hospitalization of people participated in cooperative medical in different areas in Jilin Province 2015

\begin{tabular}{|c|c|c|c|}
\hline Regions & $\begin{array}{c}\text { The number of people participated in } \\
\text { cooperative medical }\end{array}$ & $\begin{array}{c}\text { Times of } \\
\text { hospitalization }\end{array}$ & $\begin{array}{c}\text { Hospitalization rate } \\
(\%)\end{array}$ \\
\hline $\begin{array}{c}\text { The whole } \\
\text { province }\end{array}$ & 13943223 & 1808233 & 12.9 \\
\hline The east & 2964821 & 424532 & 14.3 \\
\hline The central & 7865213 & 918342 & 11.7 \\
\hline The west & 3113189 & 465359 & 14.9 \\
\hline
\end{tabular}

\subsection{Hospitalization Compensation of New Rural Cooperative Medical in Jilin Province}

Hospitalization compensation rate of New Rural Cooperative to farmers is gradually increasing in 2003-2015, but the average hospitalization fee is also increasing year by year. Per hospitalization costs were 7132 Yuan in 2015, compared with the last year, it increased by $9.2 \%$; hospitalization compensation ratio is $61.5 \%$, as shown in table 5 .

Table 5 Hospitalization cost compensation of farmers participated in NCMS in Jilin province

\begin{tabular}{|c|c|c|c|c|c|c|}
\hline & & \multicolumn{2}{|c|}{ Hospitalization fees } & \multicolumn{2}{|c|}{$\begin{array}{c}\text { Hospitalization compensation } \\
\text { fees }\end{array}$} & \multirow{2}{*}{$\begin{array}{c}\text { Hospitalization } \\
\text { Yempensation } \\
\text { rate }\end{array}$} \\
\cline { 3 - 6 } & $\begin{array}{c}\text { Hospitalization } \\
\text { times }\end{array}$ & $\begin{array}{c}\text { Total fees } \\
\text { (Ten } \\
\text { thousand } \\
\text { yuan) }\end{array}$ & $\begin{array}{c}\text { Average } \\
\text { hospitalization } \\
\text { fees (yuan) }\end{array}$ & $\begin{array}{c}\text { Amount of } \\
\text { compensation } \\
\text { (ten thousand } \\
\text { yuan) }\end{array}$ & $\begin{array}{c}\text { Average } \\
\text { compensation } \\
\text { fees(Yuan) }\end{array}$ & \\
\hline $2003-2004$ & 39266 & 8632 & 2198 & 2334 & 594 & 27.0 \\
\hline 2005 & 98772 & 16176 & 1638 & 4449 & 450 & 27.5 \\
\hline 2006 & 241328 & 51375 & 2129 & 15397 & 638 & 30.0 \\
\hline 2007 & 477236 & 124194 & 2602 & 41079 & 861 & 33.1 \\
\hline 2008 & 639827 & 200244 & 3130 & 72394 & 1131 & 36.2 \\
\hline 2009 & 742903 & 268768 & 3618 & 99957 & 1345 & 37.2 \\
\hline 2010 & 887838 & 370519 & 4173 & 151892 & 1711 & 41.0 \\
\hline 2011 & 1054371 & 508875 & 4826 & 226646 & 2150 & 44.5 \\
\hline 2012 & 1217047 & 658158 & 5408 & 345630 & 2840 & 52.5 \\
\hline 2013 & 1412353 & 763276 & 5983 & 423134 & 3465 & 55.4 \\
\hline 2014 & 1587324 & 857321 & 6532 & 517635 & 3987 & 60.4 \\
\hline 2015 & 1808233 & 987632 & 7132 & 607234 & 4586 & 61.5 \\
\hline
\end{tabular}

\section{Improvement Strategies for "New Rural Cooperative Medical System" in Jilin Province}

Based on the above research findings, this study puts forward some policy recommendations to improve the implementation effect of the new rural cooperative medical care.

Innovate the new rural cooperative operation management mode and optimize the overall compensation scheme. Under the background of new medical reform, explore and improve the level of the new rural cooperative medical system and establish the new rural cooperative operation management mode of "Province overall planning and county management". Gradually realize the province's unity of the new rural cooperative policy system, financing standards, compensation policies, fund management, service supervision, information management and other aspects [6].

Establish a new rural cooperative medical system to enlarge the insurance and enlarge the effectiveness of the new rural cooperative fund. In order to effectively solve the problem of certain 
gap existing in the guaranteeing ability of the new rural cooperative medical system and the actual needs of the farmers, explore and establish insurance system for serious illness. Actively explore and establish insurance system for serious illness led by government, set up by commercial insurance institutions, and provincial overall planned [7]. Through the establishment of NCMS supplementary insurance to provide guarantee for high medical costs for the farmers who are suffering from serious illness, further enlarge the NCMS fund guarantee efficiency, and effectively improve the security level of major diseases.

Establish the dynamic adjustment mechanism of the new rural cooperative medical system and improve the ability and level of security. In order to effectively solve the problem of a gap between existing in the basic medical insurance between urban and rural residents, it is necessary to gradually improve the financing standards, so as to improve the ability and level of the new rural cooperative medical care and perfect the new rural cooperative medical system.

\section{Conclusion}

Based on the new medical reform policy and related working papers, this paper makes an empirical analysis of the operation data of the new rural cooperative medical system in Jilin province from 2003 to 2015, and draws the conclusions as follows:

(1) In Jilin Province, the new rural cooperative medical system has made remarkable progress in the operation process, which in a certain extent reduces the economic burden of disease for the rural residents, improves the enthusiasm of peasants' medical, promotes the utilization of medical and health services for farmers participated in NCMS, and effectively alleviates the phenomenon of being supposed to be hospitalized because of economic reason causes.

(2) In Jilin Province in 2003, 6 Counties (cities) are selected to start plot of the new rural cooperative medical system, and in 2007, it has taken the lead in realizing the full coverage of the new rural cooperative medical system, namely all 67 Counties (City, District, and Development Zone) in the province have comprehensively launched a new rural cooperative medical system (NCMS), marking that the new rural cooperative medical system framework suitable for rural economic and social development has been basically established in Jilin Province.

(3) The new rural cooperative medical funds per capita will continue to improve in Jilin Province, individuals' contributions accounted for the annual income proportion is comparatively reasonable and it maintains moderate growth in the affordable scope for farmers participated in NCMS.

(4) The amount of medical expenses paid by individuals has increased, but the proportion of individuals who pay medical expenses accounted for a lower proportion of income. Individual self-paid medical expenses decrease significantly with the increase of per capita net annual income of farmers, which reflects that the level of guaranteeing ability of the new rural cooperative medical system is comparatively adaptable to the local rural economic development level in Jilin Province.

\section{References}

[1] Wang Q, Liu H, and Lu Z X. Role of the new rural cooperative medical system in alleviating catastrophic medical payments for hypertension, stroke and coronary heart disease in poor rural areas of China[J]. BMC public health, 2014, 14(1): 1.

[2] Tang S N, Jian W Y, and Yip W C. [Impact of primary care oriented outpatient benefit package design in new rural cooperative medical system on hypertension outpatient services utilization] [J]. Beijing University. Yi xue ban= Journal of Peking University. Health sciences, 2014, 46(3): 445-449.

[3] Shi L, Zhang D. China's new rural cooperative medical scheme and underutilization of medical care among adults over 45: Evidence from CHARLS pilot data [J]. The Journal of Rural Health, 2013, 29(s1): s51-s61. 
[4] Dai B, Zhou L, and Mei Y J. Regional inequity in financing new cooperative medical scheme in Jiangsu, China $[\mathrm{J}]$. The International journal of health planning and management, 2014, 29(2): e97-e106.

[5] Zhang D, Shi L, and Tian F. Care Utilization with China's New Rural Cooperative Medical Scheme: Updated Evidence from the China Health and Retirement Longitudinal Study 2011-2012[J]. International journal of behavioral medicine, 2016: 1-9.

[6] Li C, Hou Y, and Sun M. An evaluation of China's new rural cooperative medical system: achievements and inadequacies from policy goals [J]. BMC public health, 2015, 15(1): 1.

[7] Zhang Y, Chen Y, Zhang X, et al. Current level and determinants of inappropriate admissions to township hospitals under the new rural cooperative medical system in China: a cross-sectional study [J]. BMC health services research, 2014, 14(1): 1. 